九州大学学術情報リポジトリ

Kyushu University Institutional Repository

\title{
Development of Small Scale Electrohydrodynamic Drying Device for Rough Rice Using DC Plasma Generator
}

Ramadhanty, S

Department of Electrical Engineering, Faculty of Engineering, Universitas Indonesia

Amirullah, $\mathrm{MH}$

Department of Mechanical Engineering, Faculty of Engineering, Universitas Indonesia

Faturrahman, $\mathrm{M} \mathrm{H}$

Department of Mechanical Engineering, Faculty of Engineering, Universitas Indonesia

Dhelika, R

Department of Mechanical Engineering, Faculty of Engineering, Universitas Indonesia

他

https://doi.org/10.5109/2321000

出版情報 : Evergreen. 6 (2)，pp.103-107，2019-06. 九州大学グリーンテクノロジー研究教育センター バージョン：

権利関係 : 


\title{
Development of Small Scale Electrohydrodynamic Drying Device for Rough Rice Using DC Plasma Generator
}

\author{
S Ramadhanty ${ }^{1}$, M H Amirullah ${ }^{2}$, M H Faturrahman², R Dhelika ${ }^{2}$, T Abuzairi ${ }^{1, *}$ \\ ${ }^{1}$ Department of Electrical Engineering, Faculty of Engineering, Universitas Indonesia, Kampus Baru UI Dep \\ ok 16424, Indonesia
}

${ }^{2}$ Department of Mechanical Engineering, Faculty of Engineering, Universitas Indonesia, Kampus Baru UI De pok 16424, Indonesia

*Tomy Abuzairi,

E-mail: tomy.abuzairi@ui.ac.id

(Received March 8, 2019; accepted March 26, 2019).

\begin{abstract}
Indonesia, as an agricultural country, is one of rice producer countries. In the rice processing chain, drying is the most important step to be done after harvesting. Electrohydrodynamic drying (EHD) is proposed as a drying method that is faster than sun exposure and having lower power consumption compared to commercial drying machine. In this research, a design of EHD device for drying rough rice is proposed. The proposed device is based on DC plasma which is generated by a flyback transformer-based circuit with output of $2.5 \mathrm{kV}$. The device was tested with multineedle-to-plate electrode configuration with $1 \mathrm{~cm}$ distance between both electrodes and rough rice sample was placed between the electrodes for an hour. The test result showed that the change of moisture content in the rough rice treated by the proposed device is five times higher than that of rough rice treated by sun exposure. Power consumption of EHD device is only 1.3 Watt for 50 grams per hour. Moreover, the temperature of the EHD device is quite low $\left(\sim 23{ }^{\circ} \mathrm{C}\right)$ that can be considered as non-thermal device.
\end{abstract}

Keywords: DC Plasma, Electrohydrodynamic Drying (EHD), rough rice

\section{INTRODUCTION}

The drying process is understood to consume about $10 \%$ of the total energy required in the food industry ${ }^{1)}$. Especially in the value chain of agriculture, drying is considered the most important process after harvesting ${ }^{2}$. This explains why the topic of drying for agricultural produce had draws much attention from so many researchers from decades ago ${ }^{3-8)}$.

Taking the example of rice, In Indonesia the drying of rough rice generally is still conducted conventionally by solar drying method. Although it does not cost much to the farmers, this method could normally take a full day, and when the weather is unfriendly, it can take up to two to three days. Commercial drying methods, such as fluidized beds, can speed up the drying process, but they use air as a medium and are ineffective, especially in the context of smallholders in developing countries such as Indonesia, because the process is energy intensive. The use of energy is mainly for moving large volume of air at high speed ${ }^{9)}$. Consequently, a solution that can speed up the drying process of rough rice with less energy consumption is imperative to solve this problem.

Electrohydrodynamic drying (EHD) is proposed as a possible solution. Based on the principle of electrohydrodynamics, high electric fields will cause a corona discharge. Consequently, due to the ionization of the air molecules, this causes ion jets, generally known as the corona wind, to collide with the vapor moisture of the sample which in turn enhances the drying process. EHD drying had gained wider attention in the past decade due to many advantages it offers. First, this method has a low energy consumption and does not change the properties of the drying sample. Second, the drying rate of this method is claimed to be 3-4 times faster than that of the conventional method. ${ }^{10-13)}$.

Researchers had tried the method of electrohydrodynamic drying on several samples, including mushroom slices ${ }^{14)}$, rough rice $^{15)}$, potato slabs ${ }^{16)}$, sand ${ }^{17)}$, kiwi fruits ${ }^{18)}$, okara cake $^{19)}$, apple slices $^{20)}$, and Japanese radish ${ }^{21}$. However, many studies only put their focus on the experimental aspects and analysis, especially for improvements of the process parameters. On the other hand, there has been an emerging trend toward the upscaling of this method ${ }^{22,23)}$, considering the fact that there is no commercial off-the-shelf device in the market up to date. In this work, we place our focal point on rough rice, which is an important commodity in the agricultural industry in 
Indonesia. The purpose of this work is to develop a preliminary small-scale prototype design of an electrohydrodynamic-based grain drying device to dry rough rice. The design was developed and its performance was evaluated.

\section{Materials and method}

The prototype was designed to be simple without using any moving parts, easy to assemble, and portable. These three requirements were set considering the conditions of the smallholders in the field. The whole system consists of three parts, namely the power supply, high voltage generator, and the electrodes, as shown in Figure 1(a). Though generally there are two commonly used electrode designs, i.e. needle type and wire type, the scope of research in this work is limited to the needle-type corona generator.

The power drawn from the $12 \mathrm{~V}$ battery is then transformed by a high voltage generator into an adjustable voltage with the order of kilovolts. The high voltage generator consists of a flyback transformer driven by a circuit having a frequency of $12.5 \mathrm{kHz}$. The output voltage can be adjusted by a rotating dial. The dial is not linearly-scaled, meaning that lower voltage outputs will have a more accurate reading compared to higher voltage ones. The output voltage is adjustable. In this research, the output voltage is kept constant at $2.5 \mathrm{kV}$. Figure 1(b) below shows the photograph for the constructed system.

(a)
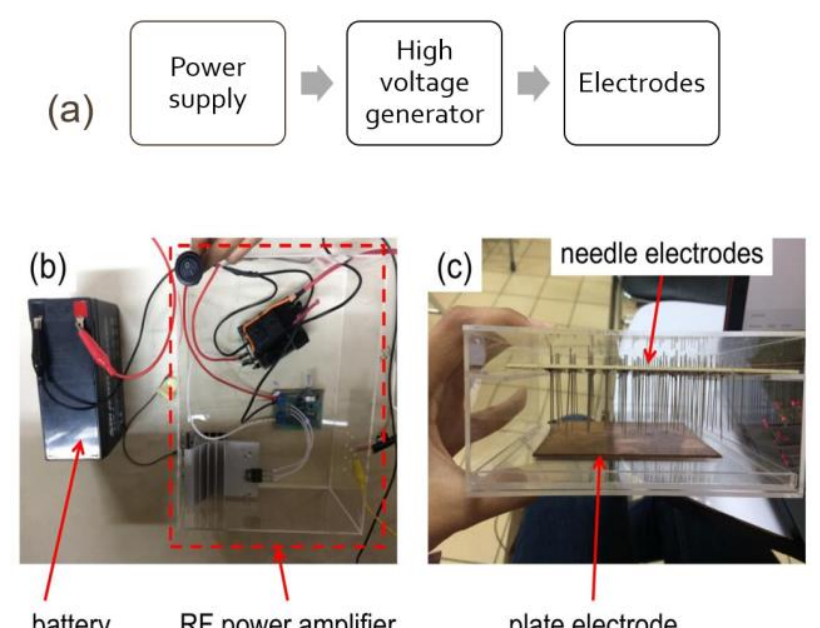

battery

plate electrode

Fig. 1: (a) whole schematic of the proposed electrohydrodynamic-based drying machine consisting of three parts, (b) photograph showing battery as the power supply and high voltage generator (c) photograph of multi-needle-to-plate electrodes.

Finally, the output voltage is being fed to the third part, which is the multi-needle corona generator. The multi-needle electrodes, affixed in an upper plate, were suspended and made sure that the corona generated could cover the area beneath. Plate electrode was prepared and was connected to the ground. The specimen, prepared inside a petri dish, was placed on top of the plate electrode. The whole system was put inside a compact container made from an acrylic. Holes were made on the acrylic walls to ensure the heat from the specimen could be released to the surrounding.

The drying experiment was conducted with $50 \mathrm{~g}$ of rough rice. The specimen, i.e. rough rice, was soaked in water overnight until it reaches the moisture content of $30 \%$. Two identical specimens were prepared, one was to be dried with the proposed EHD drying method in a room temperature of $26^{\circ} \mathrm{C}$, whereas the other one was placed under the sun exposure with a recorded temperature of $33^{\circ} \mathrm{C}$. The drying was done for one hour and the moisture content (MC) for both specimens were measured using a digital grain moisture meter TA-5. The formula for $\mathrm{MC}$ and its decrement, $\triangle \mathrm{MC}$ are given in Equation (1) and (2).

$$
\begin{gathered}
\mathrm{MC}=\frac{W_{\text {wet sample }}-W_{\text {dry sample }}}{W_{\text {dry sample }}} \times 100 \% \\
\triangle \mathrm{MC}=\mathrm{MC}_{\text {final }}-\mathrm{MC}_{\text {start }}
\end{gathered}
$$

\section{Results and discussion}

As depicted in Figure 2, moisture content (MC) in plasma-treated rough rice in a room temperature of $26{ }^{\circ} \mathrm{C}$ decreased faster, that is from $30 \%$ to $25 \%$. As a comparison, rough rice which was exposed to sunlight at 12:00 PM with a temperature of $33{ }^{\circ} \mathrm{C}$ and humidity of $60 \%$, underwent a decrement of moisture content from $30 \%$ to $29 \%$ during the same time interval. It can be inferred from the experimental data that a faster moisture content removal is caused by an increase in mass transfer rate by the corona wind of the EHD. The air ions coming from a small area around the needle point are accelerated by the applied electric force and colliding with the sample. Ions that hit the sample increase the mass transfer rate of the moisture through an increased turbulence ${ }^{24)}$. Moreover, the efficiency of the drying process also depends on the electrode configuration, with multi-needle configuration having the highest efficiency compared to wire and single electrode configuration ${ }^{25)}$. The direction of corona wind can be controlled by positioning the discharge and reception electrode ${ }^{26)}$. More needles/points also make a more even drying distribution $^{27)}$. 


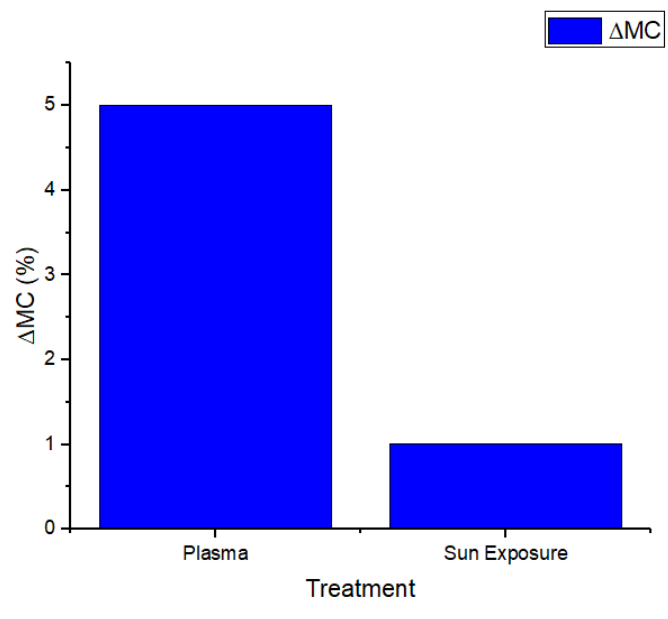

Fig. 2: Comparison of moisture content decrement in different drying methods.

Similar results were also demonstrated by experiments conducted by $\mathrm{Cao}$, et al. ${ }^{15)}$ who performed rough rice drying by multi-needle-to-plate electrode configuration using multi-needle consisting of 16 needles, a voltage of 10-30 kV and a distance between electrodes of 35-55 $\mathrm{mm}$. The drying rate on plasma treated samples were faster compared to control, and increased by about 1.16 times per $10 \mathrm{kV}$ increase. The increase of the drying speed also increases 1.16 times for every $1 \mathrm{~cm}$ reduction of electrode distance. Another example is the drying of fungi by $\mathrm{S}$. T. Dinani, et. $\mathrm{al}^{14)}$ using multicondition-to-plate configurations, $17-21 \quad \mathrm{kV}$ voltages and 5-7 cm spacing between electrodes, in which voltage increase and reduction of the spacing between electrodes speed up the drying process. Increments on the drying speed of each reference are arguably different since each experiment uses different experimental and drying specimens.

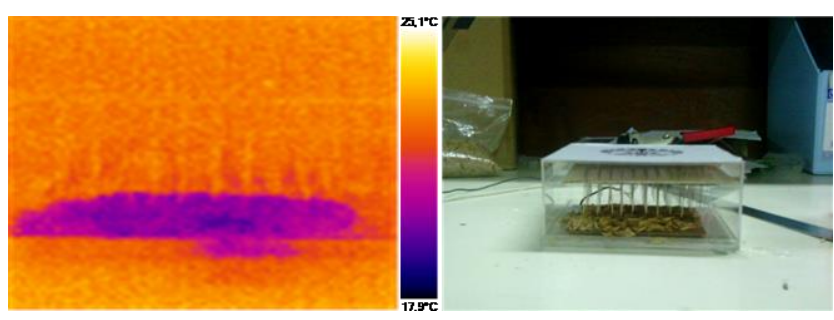

Fig. 3: Thermal image of the EHD device and rough rice.

In addition to moisture content measurements, temperature measurements were also performed using DT-9887 thermal camera. The thermal image taken using the camera is shown in Figure 3. In Figure 3, it can be seen that the rough rice did not heat up during the drying process. The temperature measurements in Table 1 shows that each electrode experienced an increase in temperature compared to the ambient temperature of the room caused by current dissipation caused by the electric current during the drying process. The drying process does not result in a significant heating on the rough rice $\left(20.5{ }^{\circ} \mathrm{C}\right)$, multi-needle electrode $\left(23.3{ }^{\circ} \mathrm{C}\right)$, and plate electrode $\left(22.2{ }^{\circ} \mathrm{C}\right)$. Therefore, it can be concluded that this device does not emit thermal energy, but rather a non-thermal one by utilizing ion jets ${ }^{4}$. Moreover, after measuring the power of EHD device, this device consumes low power energy, which is only 1.3 Watt for 50 grams per hour of rough rice. This power electricity is smaller than other method (150 Watt for 50 grams per hour) ${ }^{28)}$.

Table 1. Temperature of the EHD device and rough rice.

\begin{tabular}{|c|c|}
\hline Parameter & Temperature $\left({ }^{\circ} \mathbf{C}\right)$ \\
\hline Rough rice & 20.5 \\
\hline Multineedle electrode & 23.3 \\
\hline Plate electrode & 22.2 \\
\hline
\end{tabular}

\section{Conclusion}

In this research, a design of electrohydrodynamic drying (EHD) device for drying rough rice is proposed. The EHD device is based on a DC plasma which is generated by a flyback transformer-based circuit with an output of $2.5 \mathrm{kV}$. The device was tested with multi-needle-to-plate electrode configuration with $1 \mathrm{~cm}$ distance between both electrodes and rough rice sample placed between the electrodes for an hour. The test result showed that the proposed device could reduce moisture ratio with a drying rate faster than that of the sun exposure. Power consumption of EHD device is only 1.3 Watt for 50 grams per hour. Moreover, the temperature of the EHD device is quite low, which is the temperature on the rough rice $\left(20.5^{\circ} \mathrm{C}\right)$, multi-needle electrode $\left(23.3^{\circ} \mathrm{C}\right)$, and plate electrode $\left(22.2^{\circ} \mathrm{C}\right)$. Therefore, the EHD device can safely be considered as non-thermal by utilizing ion jets.

\section{Acknowledgements}

This work has been supported in part by Research Grant 2019 "Penelitian Dasar Unggulan Perguruan Tinggi" from the Ministry of Technology Research and Higher Education of the Republic of Indonesia. The authors also acknowledge the support of the United States Agency for International Development (USAID) through the Sustainable Higher Education Research Alliance (SHERA) Program for Universitas Indonesia's Scientific Modeling, Application, Research and Training for City-centered Innovation and Technology (SMART CITY) Project, Grant \#AID-497-A-1600004, Sub Grant \#IIE-00000078-UI-1. 


\section{References}

1) Singh, V. Orsat, and V. Raghavan, “A comprehensive review on electrohydrodynamic drying and high-voltage electric field in the context of food and bioprocessing," Dry. Technol., vol. 30, no. 16, pp. 1812-1820, 2012.

2) S. Hanif, M. Sultan, T. Miyazaki, and S Koyama, "Steady-state Investigation of Desiccant Drying System for Agricultural Applications," Evergreen., vol. 5, no. 1, pp. 33-42, 2018.

3) Ekechukwu, O. Va, and Brian Norton. "Review of solar-energy drying systems II: an overview of solar drying technology." Energy conversion and management, vol. 40, no.6, pp. 615-655, 1999.

4) V. R. Sagar, and P. Suresh Kumar. "Recent advances in drying and dehydration of fruits and vegetables: a review." Journal of food science and technology vol. 47, no. 1, pp. 15-26, 2010.

5) A. Sharma, C. R. Chen, and N. V. Lan. "Solar-energy drying systems: A review." Renewable and sustainable energy reviews vol. 13, no. 6, pp. 1185-1210, 2009.

6) M. Kumar, S. K. Sansaniwal, and P. Khatak. "Progress in solar dryers for drying various commodities." Renewable and Sustainable Energy Reviews, vol. 55, pp. 346-360, 2016.

7) M. Zhang, et al. "Recent developments in high-quality drying of vegetables, fruits, and aquatic products." Critical reviews in food science and nutrition vol. 57, no. 6, pp. 1239-1255, 2017.

8) M. H. Mahmood, M. Sultan, T. Miyazaki, S. Koyama, "Desiccant Air-Conditioning System for Storage of Fruits and Vegetables: Pakistan Preview." Evergreen, vol. 3, no. 1, pp. 12-17, 2016.

9) O. Rouaud and M. Havet, "Assessment of the electrohydrodynamic drying process," Food Bioprocess Technol., vol. 2, no. 3, pp. 240-247, 2009.

10) T. Kudra and A. Martynenko, "Energy aspects in electrohydrodynamic drying," Dry. Technol., vol. 33, no. 13, pp. 1534-1540, 2015.

11) A. Singh, V. Orsat, and V. Raghavan. "A comprehensive review on electrohydrodynamic drying and high-voltage electric field in the context of food and bioprocessing." Drying Technology, vol. 30, no. 16, pp. 1812-1820, 2012.

12) Martynenko, Alex, and Tadeusz Kudra. "Electrically-induced transport phenomena in EHD drying-A review." Trends in Food Science \&
Technology, vol. 54, pp. 63-73, 2016.

13) T. Defraeye, and A. Martynenko. "Electrohydrodynamic drying of food: New insights from conjugate modeling." Journal of cleaner production, vol. 198, pp. 269-284, 2018.

14) S. T. Dinani, N. Hamdami, M. Shahedi, and M. Havet, "Mathematical modeling of hot air/electrohydrodynamic (EHD) drying kinetics of mushroom slices," Energy Convers. Manag., vol. 86, pp. 70-80, 2014.

15) W. Cao, Y. Nishiyama, S. Koide, and Z. Lu, "Drying enhancement of rough rice by an electric field," Biosyst. Eng., vol. 87, no. 4, pp. 445-451, 2004.

16) Y. Chen, N. N. Barthakur, and N. P. Arnold, "Electrohydrodynamic (EHD) drying of potato slabs," J. Food Eng., vol. 23, no. 1, pp. 107-119, 1994.

17) A. Singh, S. K. K. Vanga, G. Raveendran Nair, Y. Gariepy, V. Orsat, and V. Raghavan, "Electrohydrodynamic drying of sand," Dry. Technol., vol. 35, no. 3, pp. 312-322, 2017.

18) M. J. Dalvand, S. S. Mohtasebi, and S. Rafiee, "Modeling of electrohydrodynamic drying process using response surface methodology," Food Sci. Nutr., vol. 2, no. 3, pp. 200-209, 2014.

19) F.-D. Li, L.-T. Li, J.-F. Sun and E. Tatsumi, "Electrohydrodynamic (EHD) Drying Characteristic of Okara Cake," Drying Technology, vol. 23, no. 3, pp. 565-580, 2005.

20) A. Martynenko and W. Zheng, "Electrohydrodynamic drying of apple slices: Energy and quality aspects," Journal of Food Engineering, vol. 168, pp. 215-222, 2016.

21) T. R. Bagjai and F. Hashinaga, "High Electric Field Drying of Japanese Radish," Drying Technology, vol. 19, no. 9, p. 2291-2302, 2001.

22) T. Defraeye, and A. Martynenko. "Future perspectives for electrohydrodynamic drying of biomaterials." Drying Technology, vol. 36, no. 1, pp. 1-10, 2018.

23) T. Defraeye, and A. Martynenko. "Electrohydrodynamic drying of multiple food products: Evaluating the potential of emitter-collector electrode configurations for upscaling." Journal of Food Engineering, vol. 240, pp. 38-42, 2019.

24) Y. Bai, B. Sun, and G. Yang, "Drying characteristics of Spanish mackerel during electrohydrodynamic (EHD) drying," presented at the Power and Energy Engineering Conference (APPEEC), Asia-Pacific, pp. 
$1-4,2011$.

25) S. A. O. Ahmedou, O. Rouaud and M. Havet, "Assessment of the Electrohydrodynamic Drying Process," Food Bioprocess Technology, vol. 2, pp. 240-247, 2009.

26) T. I. J. Goodenough, P. W. Goodenough and S. M. Goodenough, "The efficiency of corona wind drying and its application to the food industry," Journal of Food Engineering, vol. 80, no. 4, pp. 1233-1238, 2007.

27) A. Martynenko, T. Kudra, J. Yue, "Multipin EHD dryer: Effect of electrode geometry on charge and mass transfer," Drying Technology, vol. 35, no. 16, pp. 1970-1980, 2017.

28) S. Sopanronnarit, W. Rordprapat, and S. Wetchacama. "Mobile fluidized bed paddy dryer." Drying technology, Vol. 16, no. 7, pp. 1501-1513, 1998. 